\title{
Experimental Investigations on Drying of Porous Media Using Infrared Radiation
}

\begin{abstract}
A. K. Haghi
Increased interest is being shown in infrared drying today because of the environmental and technological advantages offered by this method. In order to assess the advantages of this drying process, extensive trials have been carried out. The objective of this investigation was to study the drying rate of infrared drying. This was achieved with the use of scanning pyrometer and image analysis.
\end{abstract}

Keywords: infrared dryer, porous media, drying rate, image analysis

\section{Introduction}

Drying is one of the most energy-intensive processes in many industrial fields (food industry, paper industry, textile industry, etc.). Therefore, studies of this type of problem have become very important and have for several decade attracted the attention of researchers. This article discusses an experimental study of heat transfer during the drying of porous media, using image analysis with the aim of improving process performance.

Textile drying machines are among the most expensive and most energy-consuming machines used in wet processing. Most of them consist of hot air dryers from which a proportion of the circulating air is discharged to waste as exhaust air. The air discharged from the chimney stack, represents a significant energy loss. Infrared dryers have a variety of advantages, in particular when they are used for treatment of textile sheet material in wet state. First, they permeate into and heat the textile sheet very quickly. Secondly, they heat only the required sections of the object. There is no heating of unnecessary sections of the object, thereby avoiding wastage of thermal energy. Thirdly, since infrared irradiation causes, an almost simultaneous temperature rise in different sections of an object exposed to it, regional variations in temperature within the object can be significantly reduced leading to ideal and uniform heating of the object. Finally, adjustment of the output voltage to infrared irradiation enables simple, easy and swift control of heating condition in accordance with the demands in actual treatment of textile sheet materials.

\section{Experimental}

The experiment consisted a simple $20 \mathrm{~kW}$ quartz tube laboratory infrared dryer. The dryer sends the heat to the fabric surface. An infrared camera observes the thermal scene and produces a real-time, monochrome thermal image. The analog video images are recorded on tape for the entire experiment, with later extraction of the temperature data. The IR camera, which is calibrated at certain temperature, maps the spectral radiance onto a thermal image of the fabric surface. Following image acquisition, analog video images are digitized and treated to image processing routines (algorithms) to improve the signal-to-noise ratio and transformation of useful data. This image processing system has already been described in detail in previous papers [1-6].
Generally, a typical image processing system contains three fundamental elements:

- an image-acquisition element,

- an image-processing element, and

- an image display element.

A continuous scene is converted to a digital image and stored in compacted memory by the image acquisition element. This image is displayed in some form by the image-display element for human viewing. The image-processing element is designed for various tasks, which generally fall into three main groups:

- image enhancement,

- image analysis and

- image coding.

The scanning pyrometer rests on the fabric surface, ensuring that the temperature measurement does not result in damage to the fabric.

Knowing the values of water content of the fabric before drying $\left(H_{i}\right)$ and after drying $\left(H_{f}\right)$, one can calculate the global rate of water evaporation from the fabric in the dryer at a given total power of the infrared source [7]:

$$
E V A P=\left(H_{i}-H_{f}\right) S L D
$$

Where

$S=$ speed of fabric in the oven $(\mathrm{m} / \mathrm{s})$,

$L=$ fabric width (m),

$D=$ superficial weight of dry fabric $\left(\mathrm{g} / \mathrm{m}^{2}\right)$.

The energetic efficiency $(E F F)$ may be calculated from the evaporation rate using [7]:

$$
E F F=\frac{E V A P \cdot \Delta H}{P} \cdot 100
$$

Where

$\Delta H$ is the latent heat of evaporation of water $(\mathrm{J} / \mathrm{g})$.

Alternatively, EVAP and $P$ can be expressed in units of $\left(\mathrm{g} \cdot \mathrm{H}_{2} \mathrm{O} \cdot \mathrm{m}^{-2} \mathrm{~s}^{-1}\right)$ and $\mathrm{W} \cdot \mathrm{m}^{-2}$ respectively.

Equation (2) predicts that EVAP will be directly proportional to $P$ provided $E F F$ remains constant. The value of $E F F$ applies only to this particular dryer and depends on the operating conditions.

The characteristics of the various fabrics in this drying study are given in Table 1. 
Table 1: Fabrics used in the drying study

\begin{tabular}{|c|c|c|}
\hline FABRIC & FIBER & WEIGHT, $\mathrm{g} / \mathrm{m}^{2}$ \\
\hline $\mathrm{A}$ & COTTON & 130 \\
\hline $\mathrm{B}$ & POLYESTER & 150 \\
\hline
\end{tabular}

In the drying process, water is evaporated from the exposed yarn surfaces and replaced by water migration from within the fabric structure. During this process, a steady state is established and the fabric temperature and evaporation rate remain almost constant. At the of the so-called constant rate drying period, the fabric temperature begins to increase and the rate of evaporation decreases, because below a certain critical water content migration of liquid water, and later water vapor, to the exposed surfaces becomes more difficult and eventually ceases.

\section{Results and Discussion}

The drying curves obtained (Fig. 1) show moisture content versus time. The slope of this curve is the drying rate, the rate at which moisture is being removed. The curve begins with a warm-up period, where the material is heated. The drying rate can be negative in the warm-up period. As the material heats up, the rate of drying increases to a peak rate that is maintained for a period of time known as the constant rate period. Eventually, the moisture content of the material drops to a level known as the critical moisture content, where the high rate of evaporation cannot be maintained. This is the beginning of the falling rate period.

The greatest effects of humidity on the moisture content versus time curves occur in the warm-up and constant rate periods. Once the critical moisture content is reached, the curves are similar. In the second falling rate period, humidity

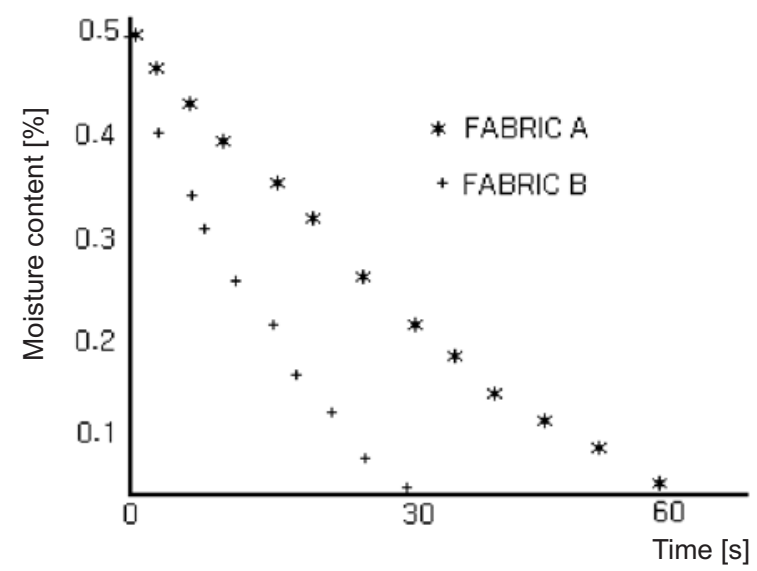

Fig. 1: Moisture content versus time

has little effect on the time required to remove an increment of moisture.

The warm-up period corresponds to the region where moisture content is the highest and the drying rate is rapidly changing. The plots reveal that the warm-up period is relatively short and represents a small part of the total drying time.

An image analysis of the surface is shown in figure 2. The shape of the wave is influenced by the pore size distribution of the fabric. The flat region of the surface depicts the highest temperature. In phenomenological terms, the fabric reaches a critical temperature when there is an irreversible shift in the heat balance between the heat generation rate and the heat losses. Therefore, factors such as fabric orientation affect the measurement of this parameter. As weight increases, the temperature of the fabric increases at slower rate. This is as expected, because increasing fabric thickness increases the

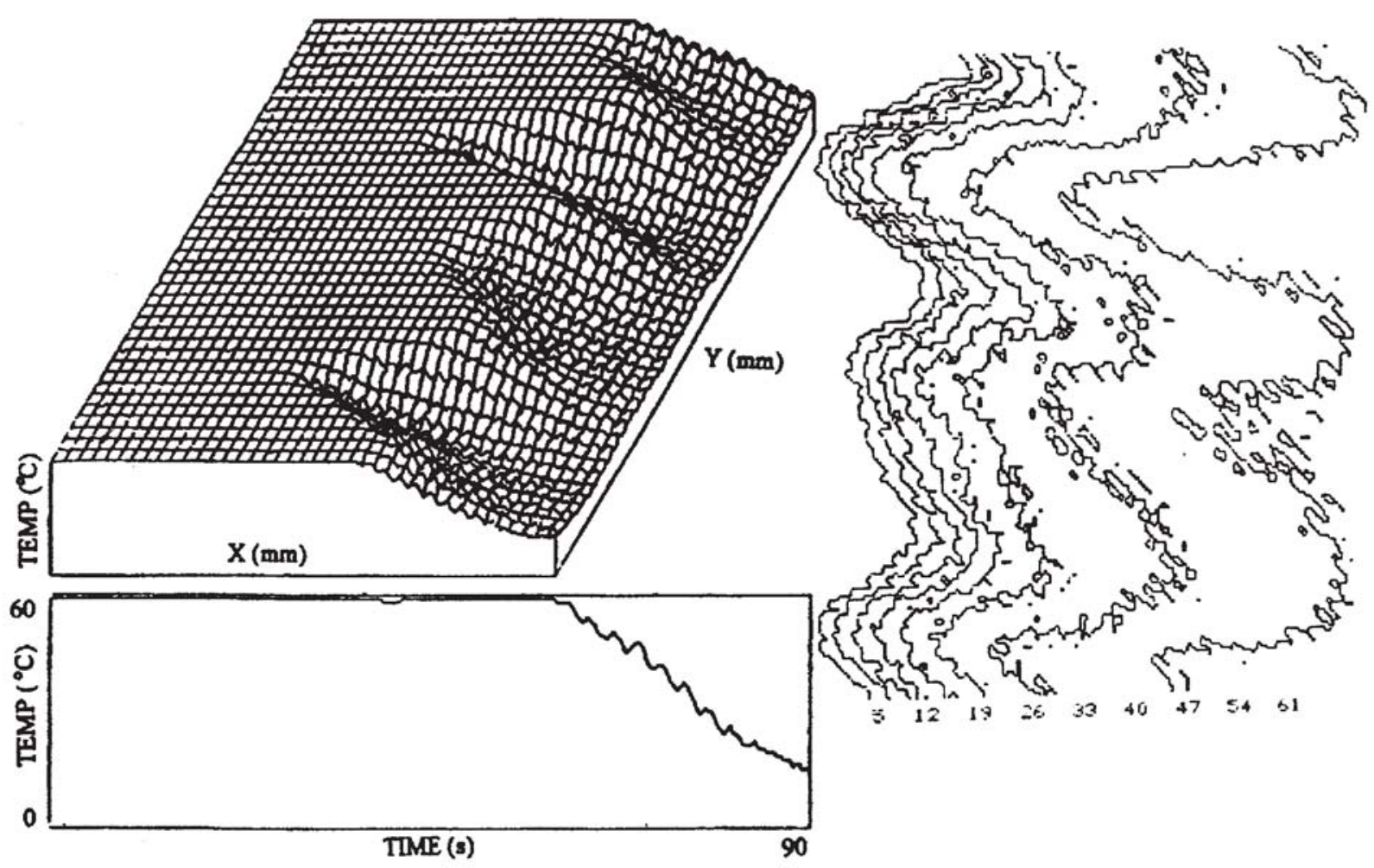

Fig. 2: Surface temperature distribution at 90 seconds and surface isothermal distribution 
internal resistance to heat transfer within the fabric. The surface isotherm distributions are also shown in figure 2. The fabric surface temperature depends on the balance between the rates of heat generation and heat loss. Surface radiation is a major part of the total heat losses and depend strongly on the surface temperature. A small change in surface temperature leads to significant changes in surface heat losses. The surface isotherm vary with the fabric properties, including weight, construction and porosity. The irregularity of the isothermal contour lines is due to surface non-uniformities and yarn structure.

\section{Conclusions}

In this study, the rate of drying was essentially independent of the nature of the fabric type, provided the final water content was not much below the critical value corresponding to the end of the constant rate drying period. The drying rate in the constant rate period decreases with increasing humidity if the temperature is low enough to prevent thermal damage. Humidity had little effect in the falling rate period.

\section{References}

[1] Haghi, A. K.: An Experimental Approach for Study of Heat Dissipation from the Surface of Small Electric Machines. The Annals of the Stefan Cel Mare University, Romania, 2000, 7 (13), pp. 66-70

[2] Haghi, A. K.: A Thermal Imaging Technique for Measuring Transient Temperature Field - An Experimental Approach. The Annals of the Stefan Cel Mare University, Romania, 1999, 6 (12), pp. 73-76
[3] Haghi, A. K. et al.: Determination des Coefficients de Transfert de chaleur lors du Sechage. $2^{\text {nd }}$ Int. Conference on Development \& Application Systems Proc., Romania, 1994, pp. 189-196

[4] Haghi, A. K.: Determination of Heat Transfer Coefficients during the Process of Through Drying of Wet Textile Materials with an Optico-Mechanical Scanning Pyrometer \& IR Thermograph. $3^{\text {rd }}$ Int. Conf. on Development \& Application Systems Proc., Romania, 1996, pp. 25-32

[5] Haghi, A. K.: Controle de Materiaux par Thermographie Infrarouge: Modelisation et Experiences, 4th Int. Conf. on Development \& Application Systems Proc., Romania, 1998, pp. 65-76

[6] Haghi, A. K. et al.: Determination des Coefficients de transfert de chaleurs lors du Sechage de Textiles par Thermographie Infrarouge et Microscopie Thermique a Balayage. Poster Presentation, SFT, Paris, France, 1994

[7] Broadbent, A. D.: Predrying of Textile Fabrics with Infrared Radiation, Textile Res. Journal, 1994, 64 (3), pp. 123-129

Dr A. K. Haghi

University of Guilan

P.O.Box 3756

Rasht

IRAN

e-mail: Haghi2002@yahoo.com 